\title{
VIGÉSIMO TERCER SUPLEMENTO BIBLIOGRÁFICO
}

\author{
Joseph T. Snow \\ Michigan State University
}

Quisiera dar las gracias a las siguientes personas por haberme o facilitado copias de, o datos sobre, unas de las entradas de este suplemento: H. Sharrer, R. Utt, A. Calderone, G. Illades Aguiar, M. I. Aboal, A. Gimber, R. Beltrán, A. Deyermond, J. Benito de Lucas, C. Parrilla, O. Di Camillo, I. Wolf, A. Gargano, J. Martín-Aragón, I. Michelena, F. Requena, F. Rojas, L. Rouhi, A. Rodríguez Jiménez, B. Taylor, S. Ríos, F. J. Lobera, y C. Wasick. Que conste: este suplemento extiende mi bibliografía del año 1985 [Celestinaby Fernando de Rojas:An Annotated Bibliographyof World Interest 1930-1985, publicado en Madison, Wisconsin por la Hispanic Seminary of Medieval Studies, y hoy agotada]. Una nueva versión ya emprendida cubrirá los años 1899-1999.

1083. ABOAL SANJURJO, María Isabel. "La recreación del mito en el teatro de Alfonso Sastre: Tragedia fantástica de la gitana Celestina." Tesina de licenciatura, noviembre de 1988. Director: Mariano de Paco.

Se trata de una traducción al escenario moderno y un nuevo contexto cultural para Celestina. Unos temas son: el equiparar el amor con la muerte, la oposición de personalidades, y el mito de Celestina para con todos los que la rodean.

1084. ALONSO, Eduardo. "Celestinas, pócimas y filtros de amor: Calisto, Melibea y una puta vieja." Leer 25, no. 103 (junio 1999), 94-95 (ilustrado).

Dos páginas escritas para caracterizar escuetamente a Rojas, su tiempo y su obra para un público lector popular. 
1085. AMESTOY, Ignacio. "Celos y amor de una obra pionera" (El mundo, 19 mayo 1999), pág. 66.

Aquí publicado aparte, tenemos el prólogo a la edición para lectores de este diario (ver 1174, abajo). El título tiene poco que ver con el contenido.

1086. AMOROS, Andrés. "El llanto de un padre (Fernando de Rojas. La Celestina), "en su Momentos mágicosen la literatura (Col. Literatura y Sociedad 65, Madrid: Castalia, 1999), 189-201.

Una lectura (en la sección, «La muerte») de los temas del planto de Pleberio que quiere establecer vínculos con actitudes análogas en otras obras de la literatura universal.

1087. ARDILA, John G. "Una traducción 'políticamente correcta': Celestina en la Inglaterra puritana." Celestinesca 22.2 (1998),33-48.

Se trata de la traducción inglesa de James Mabbe (1631) y cómo la adecuó a un público lector escrupuloso y puritano. Ilustrado con ejemplos en varias categorías de transformaciones del texto original.

1088. BALCELlS, J. M. "Los poetas de este siglo," en Diario Córdoba, Cuadernos del Sur (9 dic. de 1999), 29 (ilustrado).

La influencia de Celestina en poetas del siglo XX, en composiciones de Julián Andúgar (1959), Manuel Mantero (1974-1975;1988²), $\mathbf{M}^{\mathrm{a}}$ Victoria Atencia (1980), J. Benito de Lucas (1983), Antonio Piedra (1986), José Hierro (1998) y Rafael Ballesteros (1999).

1089. BELTRÁN, Rafael, "Cuatro escenas de comedia en La Celestina y la celestinesca: filiación genérica de la acción dramática," en Bulletí de la Societat Castellonenca de Cultura 74 (enero-junio 1998) [ = Cultura $i$ humanisme en les lletres hispàniques(s.XV-XVI), ed. G. Colón \& Ll. Gimeno], 213-234.

Tiene un efecto de crear género la comedia latina, Pamphilus, para obras posteriores (Libro de buen amor, Corbacho, Celestina, Comedia Serafina, Penitencia de amor, Segunda Celestina, etc.). Los ejemplos aducidos enriquecen cuatro situaciones dramáticas: las reacciones del amante y la amante en el primer encuentro; el obstáculo de la madre; la exploración del cuerpo en la cama; y el encuentro amoroso final. 
1090. BENITEZ, R. J. "Su contemporaneidad," en Diario Córdoba, Cuadernos del Sur (9 dic. de 1999), 36-37 (ilustrado).

Un hijo de conversos, al pintar cínicamente el lado oscuro de las glorias españolas finiseculares en su Celestina, logra crear un retrato de las pasiones desnudas universales que siguen vigentes en nuestra época.

1091. BENITO DE LUCAS, Joaquín. Antinomia (poemas 1975-1981).S. 1: Asociación Cultural La Celestina V Centenario, 1999. 120 pp.

Nueva edición del poemario de 1983 hecha para el V Centenario con un prólogo por N. Salvador Miguel e ilustraciones de Teo Puebla. Recreación en 36 poemas de importantes hitos del diálogo amoroso (Celestina-Melibea-Calisto).

1092. BLANCO AMOR, Eduardo. "Un refaixo pra Celestina: farsa de tema terxiversado." Adaptación e dramaturxia de Antonio Francisco Simón. Col. Centro Dramático Galego, Santiago de Compostela: IGAEM, 1993. 160 págs. llustrado.

El texto de la representación (original en español) traducido al gallego (75-150) con 8 fotos (blanco y negro) de los ensayos (153-160) y varias más de la escenografía y figurines (a todo color, 15-28). En 3134 figura la música de Michel Canadá compuesta para la representación. Luis Pérez Rodríguez aporta un estudio, "Eduardo Blanco Amor y o teatro popular" (43-73) que incluye interesantes observaciones a esta obra. La capa del libro lleva reproducido el cartel diseñado por el director, Antonio F. Simón. Aparte de las ilustraciones aquí, se encuentran cuatro de color de la representación misma en 1984-1994Dez Anos do Centro Dramático Galego (Santiago de Compostela: IGAEM, 1995), págs. 150-153.

1093. BLAY MANZANERA, Vicenta, y D. S. SEVERIN. Animals in Celestina, PMHRS 19, London: Dept. of Hispanic Studies, Queen Mary \& Westfield College, 1999.48 pp.

Una presentación de los animales es Celestina, acto por acto (incluyendo los pre-y posliminares), con un Registro alfabético y una bibliografía de estudios sobre estos animales.

1094. BOTTA, Patrizia. "Un 'best-seller' del Siglo de Oro." La Voz de Galicia. secc. "Culturas» (27 abril, 1999), 7. 
Buen resumen de las ediciones (lugares, fechas), continuaciones, imitaciones y traducciones del s. XVI en una demostración del estado de 'best-seller' de Celestina.

1095. . " «...y nuevamente añadido el Auto de Traso y sus compañeros". Ínsula, no. 633 (sept. 1999), 9-11 (ilustrado).

Sobre las menciones de 'Traso el coxo' en la Tragicomedia a la confección de un auto aparte (ed. Toledo 1526): he aquí unas observaciones a la onomástica usada para sus personajes, a su lenguaje y ajustes/desajustes con la obra original y, al final, la poca cabida del Auto en la tradición editorial.

1096. _ . El texto de la Celestina en la edición de Valencia, 1514," en Tragicomedia de Calisto y Melibea (Valencia, Juan Joffre, 1514). Estudios y edición paleográfica (Valencia: Inst. Alfons el Magnànim, 1999), 17-29.

Valora la importancia de las ediciones valencianas, y de las de Juan Joffre en particular $(1514,1518)$, y pormenoriza la participación del humanista Alonso de Proaza como corrector, no sólo de estas ediciones sino, probablemente, de otra (la "perdida" de Salamanca 1500, haya sido Comedia o Tragicomedia).

1097. BRIESEMEISTER, Dietrich. "La Celestina latina. Comentario y versión humanista de Kaspar von Barth (1587-1658), "en Teatro español del Siglode Oro, ed. Chr. Strosetzki (Frankfurt/Main: Vervuerte, 1998), 61-67. (*)

1098. BROCATO, Linde M. "'Tened por espejo su fin': Mapping Gender and Sex in Fifteenth- and Sixteenth-Century Spain," en Queer Iberia: Sexualities, Cultures, and Crossings from the Middle Ages to the Renaissance, ed. J. Blackmore \& G. S. Hutcheson (Durham; London: Duke UP, 1999), 325-365.

Lectura y análisis de tres obras que reflejan preocupaciones con género y sexo: Laberinto de Fortuna (Mena), Celestina (Rojas), y el anónimo Carajicomedia. Es el laberinto urbano e inmoral que centra Celestina y su presentación de la mujer y el comercio sexual como fuentes de los males sociales. En Celestina estamos metidos en ese mundo, mientras Mena se mantiene algo distante. 
1099. CALDERONE, Antonietta. "Melibea no quiere ser mujer: Un testo in piu nella "Celestinesca» contemporanea." Magisterium (Messina) 1 (1997), 793-840.

Una extensa indagación en las fuentes utilizadas por Juan Carlos Arce en su novela de 1991, Melibea no quiere ser mujer. El estudio de Gilman (La España de Fernando de Rojas) es una parte, la Tragicomediaotra parte, y la creatividad de Arce la tercera que, en su conjunto, ingenian la historia cuyo sorprendente protagonista es el mismo Fernando de Rojas.

1100. CANET, José Luis. "La filosofía moral y la Celestina." Ínsula, no. 633 (sept. 1999), 22-24 (ilustrado).

La ética, o filosofía moral, que domina en Celestina desde las declaraciones de los materiales preliminares se toman muy en serio en esta exposición del texto celestinesco. Todas las normas transgredidas voluntariamente por los personajes (se enfoca aquí más en los amantes) reciben su merecido castigo "civil y religioso."

1101. _. "Alonso de Proaza," en Tragicomedia de Calisto y Melibea (Valencia, Juan Joffre,1514). Estudiosy edición paleográfica(Valencia: Inst. Alfons el Magnànim, 1999), 31-38.

La carrera intelectual del humanista-lulista,. Proaza, y sus actividades de corrector y, posiblemente, editor, de algunas Celestinas.

1102. . "El impresor valenciano Juan Joffre, "en Tragicomedia de Calisto y Melibea (Valencia, Juan Joffre, 1514). Estudios y edición paleográfica (Valencia: Inst. Alfons el Magnànim, 1999), 39-52.

Datos bio-bibliográficos sobre el impresor valenciano de dos Celestinas $(1514,1518)$.

1103. CASARIEGO CORDOBA, Martín. "El primer amor (La Celestina, Romeo y Julieta, El diablo en el cuerpo, El sueño de los héroes), "en su El amor y la literatura (Madrid: Anaya, 1999), 33-44.

Señala muy a la ligera el paralelo entre Calisto-Melibea y HeroLeandro, el lenguaje descarnado, el amor como caza y como religión, y el amor trágico (tentativamente atribuido al estado de converso de Rojas). 
1104. CHERCHI, Paolo, \& J. T. SNOW. "Cornelius Agrippa and Celestina." Celestinesca 22.2 (Otoño 1998), 61-67.

Demuestra Agrippa en su De incertitudine (1530, pero escrito antes) un claro conocimiento del texto de la Tragicomedia.Y coloca la obra al lado de obras del mundo clásico, aumentando su fama. De Agrippa pasa directamente sus comentarios a Celestina a textos en italiano, francés, español e inglés.

1105. CONDE, Luis. "Celestinas, pócimas y filtros de amor: dietario de brebajes y conjuros," Leer 25, no. 103 (junio 1999), 90-92.

Celestina como una medium más en la consecución del deseo erótico, una línea que se inicia en la Biblia y se extiende a Laura Esquivel y Viagra.

1106. CUESTA, M. L. "Los lazos familiares," en Diario Córdoba, Cuadernos del Sur (9 dic. de 1999), 24-25 (ilustrado).

Recopila la terminología referida a parentesco en Celestinay establece dos conclusiones: el eje de la obra es Celestina, y las falsas relaciones familiares se superponen a las auténticas.

1107. DEYERMOND, Alan. "Motivación sencilla y motivación doble en la Celestina." Ínsula, no. 633 (sept. 1999), 13-15 (ilustrado).

Defiende, primero, el papel activo de la brujería en la trama de Celestina. Luego, apunta las múltiples motivaciones (1) en la transformación de Pármeno, (2) en tanto Pármeno como en Sempronio para el asesinato de Celestina y (3) en Pleberio al querer - y dotar con herencia - a su hija.

1108.DiCAMILLO, Ottavio. "Etica humanística y libertinaje," en Humanismo y literatura en tiempos de Juan del Encina (Salamanca: Universidad, 1999), 69-82.

Sugiere, limitándose al primer auto, la presencia en Celestina de un libre pensamiento material que delata huellas de los sistemas éticos paganos discutidos entre humanistas del s. XV, en los nuevos valores defendidos por Celestina (casi todo temas aparecidos en Lorenzo Valla, De vero falsoque bono), en el discurso anti-autoritario, en la 'devoción exterior' que señala un camino divergente del de la certidumbre dogmática defendida por las instituciones oficiales. En fin, un epicureísmo renovado por los humanistas del s. XV. 
1109. DIEZ BORQUE, J. M. "Fuente de inspiración en los siglos de Oro." La aventura de la Historia, 1.12 (oct. 1999), 68-71 (ilustrado).

Un breve recorrido por las letras de los siglos XVI y XVII (autores, títulos, citas) con el propósito de sugerir la canonicidad de Celestina desde casi su primera publicación.

1110. DIEZ DE REVENGA, F. J. "'Todo por vivir,'" en Diario Córdoba, Cuadernos del Sur (9 dic. de 1999), 27-28 (ilustrado).

Es un comentario al extenso poema de Jorge Guillén, «Huerto de Melibea” (1954), notando que sus posibilidades dramáticas fueron realizadas por César Oliva (Murcia, 1993).

1111. DUESO, José (ed.). La rebotica de la madre Celestina. San Sebastián: Roger, 1998.

Título engañoso; la obra de Rojas no tiene nada que ver.

1112. ECHEGOYEN, Regina N. "La Celestina: su función intertextual en Terra Nostra." Nueva Revista del Pacífico(Chile), nos. 33-36 (19881991), 243-250.

Tiene dos funciones la figura de Celestina (personaje y obra) en la novela de Carlos Fuentes: remitirnos al contexto medieval (como texto) y recordar y repetir el pasado (como personaje).

1113. ENGLAND, John. "'Testigos de mi gloria': Calisto's Bestial Behavior." La corónica 28.2 (Spring 2000), 91-100.

A la luz de ideas medievales negativas sobre el exhibicionismo (Agustín, Llull, Juan Ruiz), se presenta nuevamente la declaración de Calisto (acto XIX): "Bien me huelgo que estén semejantes testigos de mi gloria." En la versión Comedia, su comportamiento está casi inmediatamente castigado con su muerte, efecto diluido en la Tragicomedia.

1114. ESCUDERO, Juan M. "La expresión «comedor/comendador de huevos asados» en la Celestina. Nuevos asedios interpretativos." Rivista de Filologia e Letterature Ispaniche 1 (1998), 197-201.

Repasa las aportaciones al esclarecimiento del pasaje traídas a colación por Gillet, Goldman, Garci-Gómez, Kish \& Ritzenhoff, Marciales y Fernández Rivera, a los cuales añade un pasaje nunca citado (de Juan 
de Otálora en su Coloquios de Palatino y Pinciano) que pretende explicar mejor el sentido contextual: hace que Pármeno admire el cornudo paciente que tenía que haber sido el marido de Celestina al yuxtaponer lo dicho con esto: "¿Qué quieres más? Sino que si una piedra topa con otra, luego suena: iputa vieja!». Es decir, es para dar risa.

1115. FERNÁNDEZ, Sergio. "La comunicación del bien," en su Figuras españolas del Renacimiento y el Barroco (México: UNAM, 1996), 2330. $\left({ }^{*}\right)$

1116. FLORES CERVANTES, Marcela. "Individuación de la entidad en los orígenes de leísmo, laísmo y loísmo," en Cambios diacrónicos en el español,ed. C. Company (Publicaciones de Medievalia, 15, México: UNAM, 1997), 33-63.

Se estudian estos tres fenómenos en contextos diacrónicos - el Cid, la General estoria y Celestina - a la luz de tres binomos: masculinofemenino, animado-inanimado y singular-plural.

1117. FRADEJAS, José. "Cinco siglos de historia," en Diario Córdoba, Cuadernos del Sur (9 dic. de 1999), 4-5 ((ilustrado).

Acercamiento general a la trama y los personajes, y de su presencia posterior en las letras españolas.

1118. GARCÍA-FUENTES, Enrique. "Enigmas y soluciones," en Diario Córdoba, Cuadernos del Sur (9 dic. de 1999), 8-9 ((ilustrado).

Breves observaciones a los problemas de autoría, la raza del autor, y el género de la obra. No se ofrecen "soluciones" a ellos.

1119. GARCIA MONTERO, Luis. Ver 1186.

1120. GARCÍA-SABELL, Domingo. "O segredo de Celestina." La Voz de Galicia, secc. «Culturas» (27 abril 1999), 5.

La ventaja de la alcahueta, su 'secreto', es su cabeza fría, sus 'intelectuales ojos'. Y en este secreto reside su gran humanidad.

1121. GARGANO, Antonio. "'Son joi celar': Segretezza d'amore e desiderio d'esibizione nella Celestina. "Rivista de Filologia e LetteratureIspaniche 1 (1998); 9-46. 
Compara y contrasta, con mucha documentación, dos casos del "deseo de exhibición" en Celestina: el de Calisto quien - en cuatro ocasiones - quiere que otros sepan de sus amoríos con Melibea y así comete una gran infracción contra la más seria ley del amor cortés (celar o mantener la relación en el secreto más absoluto) y el de Pármeno con Areúsa que el criado quiere compartir (según el modelo del deleite que le había mostrado Celestina en el primer auto) y hablarlo con otro (auto VIII). La distinción de clases y códigos permite que veamos que la intencionalidad textual ha sido de provocar la risa en el caso de Calisto, subrayando la naturaleza paródica de su caracterización.

1122. GARRANDES, Alberto. "Los divinos excesos," en Diario Córdoba, Cuadernos del Sur (9 dic. de 1999), 18 (ilustrado).

Rojas como visionario, intérprete del espíritu de una nueva época, precursor del barroco.

1123. GERLI, E. Michael. "Dismembering the Body Politic: Vile Bodies and Sexual Underworlds in Celestina," en Queer Iberia: Sexualities, Cultures, and Crossings from the Middle Ages to the Renaissance, ed. J. Blackmore \& G. S. Hutcheson (Durham; London: Duke UP, 1999), 369-393.

Centrado en el discurso doble (Elicia y Areúsa) de condena a Melibea, su cuerpo y todo lo que ella representa en el auto IX de Celestina, el autor medita en el discurso como subtexto para una fuerte crítica ideológica al contaminado cuerpo político-moral que ostentaba la sociedad finisecular que da vida y coherencia a esta obra.

1124. GONZÁLEZ ECHEVERRIA, Roberto. La prole de Celestina. Spain: Ed. Colibrí, 1999.

Traducción española de su Celestina's Brood (1993), con una introducción especial a esta edición. El ensayo sobre Celestina se encuentra en las págs. 19-57.

a. El País (11 dic. 1999), "Babelia," p. 12, C. G. G.;

1125. GONZÁLEZ FERNÁNDEZ, María Jesús, "Sobre la motivación semántica de las expresiones pleonásticas de movimiento: Subirarriba, bajar abajo, entrar adentro y salir afuera," en Cambios diacrónicos en el español, ed. C. Company (Publicaciones de Medievalia, 15, México: UNAM, 1997), 123-141. 
Varios ejemplos de estas expresiones en Celestina, entre otras obras de la Edad Media española, nos ayudan a ver que la presencia de la meta de la acción hace que en estos contextos las expresiones no son verdaderamente redundantes porque identifican -esquemáticamente - los espacios de las acciones.

1126. GOYTISOLO, Juan. "Un universo de ruido y furia." El País (17 abril 1999), 38-39.

Heredero de Castro y Gilman, Goytisolo ve la clave del desabrido ataque que hay en Celestina contra los códigos y convenciones sociales de la época (demasiado ocupados con el materialismo y poder) al destacar la psicología de un judeo-converso que vive desviviéndose, y que proyecta sus tensiones existenciales sobre su creación literaria.

1127. . "Celebrating the $500^{\text {th }}$ Anniversary of Spanish Literature's Most Audacious and Subversive Work," Los Angeles Times (June 20), 8-9 (Book Review Section).

Una traducción de Peter Bush al inglés de la entrada 1126.

1128. HAMILTON, Michelle M. "Celestina and the Daughters of Lilith." Bulletin of Hispanic Studies (Liverpool) 75 (1998), 153-172.

Traza muchas casos análogos entre las alcahuetas de diversos textos hebreos y árabes y su reflejo en Celestina (tipos, actividades, características, comportamientos). Luego pretende descubrir en la alcahueta española ecos de la figura negativa, diabólica, de Lilith (la primera mujer de Adán), ecos que luego pasan, según la autora, a Melibea a la medida que ésta evoluciona en el texto.

1129. HERMENEGILDO, Alberto. "Los signos condicionantes de la representación: el bloque didascálico," en Critical Essays on the Literatures of Spain and Spanish America, ed. L. T. González del Valle \& J. Bueno (Boulder: Society of Spanish and Spanish-American Studies, 1991), 121-131.

Sin hablar de género, presenta en líneas generales el caso para la "inimitable teatralidad" del texto de la Celestina original. En su análisis de las marcas de teatralidad del primer auto [publicado en Incipit 11 [1991],127-151], demuestra que el diálogo celestinesco está lleno de signos portadores de su potencialidad teatral. 
1130. HERRERO RUIZ DE LOIZAGA, F. J. "El coloquio en el s. XVI: cortesía, tratamiento y vocativos en la Segunda Celestinade Feliciano de Silva, "en Oralia. Análisis del discurso oral 2 (1999), 221-239.(*)

1131. ILLADES AGUIAR, Gustavo. 'La Celestina'en el taller salmantino. Publicaciones Medievalia 21, México: UNAM, 1999. Rústica, 163pp.

Libro que va a provocar mucha discusión. Amplía, usando conceptos de diálogo encontrados en Gilman y Bajtín, la noción del taller de pintores para describir un taller de estudiantes-autores conversos en Salamanca, de cuyo gran diálogo surge el texto celestinesco, tan marcado por sus múltiples dialogismos. Aunque supone que otros miembros del "taller" podrían haber incluído a Luis de Lucena y el bachiller Sanabria, este estudio presenta el diálogo entre Celestinay varios libros de Francisco de Villalobos, contemporáneo de Rojas: Sumario de la medicina, Sentencias y su traducción del Anfitrión. Interesantes discusiones del género, de su último sentido y de la pluriautoría.

1132. INFANTES, Víctor. "Viejas y nuevas ediciones," en Diario Córdoba, Cuadernos del Sur (9 dic. de 1999), 3.

Nota la aparición en 1999 de tres ediciones facsimilares (Burgos 1499; Valencia 1514;Zaragoza 1507)de Celestina, pero da énfasis particular a Zaragoza 1507 por ser de un ejemplar completo, desconocido hasta su adquisición en 1998, y por ser un volumen facticio (la Tragicomedia encuadernada con otras tres obras en pliegos sueltos).

1133. IZQUIERDO-VALLADARES, R. "El tópico del 'carpe diem' en la Celestina y en la Comedia Thebaida." Revista de Folklore, no. 223 (1999), 9-19.

Una reseña de la literatura reciente sobre el tema que pasa revista de - entre otras cosas - el libro de D. Hartunian (1992) sobre Celestina y el «carpe diem».

1134. LACARRA LANZ, Eukene. "Los dichos 'lascivos' en La Celestina. "La Voz de Galicia, secc. «Culturas» (27 abril 1999), 6.

Ilustra con citas explicadas la comicidad a lo vivo de Celestina y, de paso, algunas de las expresiones de doble sentido (p. ej., el uso de 'andar' para el acto sexual). 
1135. (ilustrado).

Análisis de la 'enfermedad' de Calisto (causas, síntomas, curas) con vistas a determinar si la condena del desordenado apetito del incipit de la obra es consecuente con las acciones en el texto. Lo es.

1136. . "El mundo prostibulario," en Diario Córdoba, Cuadernosdel Sur (9 dic. de 1999), 11-12 (ilustrado).

Recreación del ambiente urbano y bullicioso de Celestina. En este ambiente no hay nadie cuya actuación y cuyo destino no se vea afectado por el mundo prostibulario regentado por la alcahueta como realización de los mensaje de los paratextos preliminares del texto.

1137. LAGO, Natalia. "La gran seductora del teatro más universal". El mundo (19 de mayo 1999), pág. 67.

Recuerda unas Celestinas españolas en teatro y ballet desde 1941 hasta 1999.

1138. LIE, Nadia. "The Author as Hymen. Fernando de Rojas' La Celestina Between Stephen Gilman and Michel Foulcault," en Critical SelfFashioning: Stephen Greenblatt and the New Historicism, ed. J. Pieters (Frankfurt an Main/New York: Peter Lang, 1999), 44-58.

Esta interesante discusión de la construcción de un autor (en $L a$ España de Fernandode Rojas) juega con ideas del 'nuevo historicismo' sobre el concepto de autor hechas relevantes por Foulcault. Como a Celestina, remendadora de virgos, se le ve a Gilman paralelamente cosiendo textos como autor del carácter de Rojas (más que como lector de un texto escrito por Rojas).

1139. LOBERA SERRANO, F.J. "Fernando de Rojas «que escribió Melibea». Ínsula, no. 633 (sept. 1999), 6-7 (ilustrado).

Declaración de fe en una nueva posibilidad de autoría a la vez única y doble: Rojas sí conoció una obra de otro autor desconocido; la reescribió y la terminó. Aun si hubiera lecturas orales de partes del texto, sugerencias de amigos, y otras manos que ayudaron en su preparación para la imprenta, todo podría haber pasado por la mano de Rojas. 
1140. . "La Celestina: Redacciones, testimonios y ediciones modernas" (impreso por el autor). $23 \mathrm{pp}$.

Un comentario, primero, al tipo de ediciones publicadas entre 1822 [Amarita] y 1911 [Holle] y, segundo y más extenso, un comentario a cinco ediciones híbridas que cometen el "pecado original" de seguir con la doble redacción de la Comedia y Tragicomedia, mezclándolas. Y son: las de Cejador (Clásicos Castellanos), Criado de Val-Trotter (CSIC), Severin (Alianza), Severin (Cátedra) y Russell (Castalia). En el futuro hay que desandar este camino y publicar o Comedias o Tragicomedias (los textos que leyeron los lectores antes de Amarita).

1141. LÓPEZ CASTRO, Armando. "La vieja y María Parda," en Diario Córdoba, Cuadernos del Sur (9 dic. de 1999), 22-23 (ilustrado).

Celestina es una creación completa con todos sus apetitos, entre los cuales se distingue el vino. Las alcahuetas de Gil Vicente son tipos menos desarrollados y sólo una muestra la misma afición al vino (en «O pranto de María Parda»). Tanto Rojas como Gil Vicente conocían bien las fuentes latinas y castellanas del tipo; se postula que la poca adhesión de Vicente a la obra de Rojas se debe al ateísmo de éste.

1142. LÓPEZ-RÍOS, Santiago (ed), ver SALVADOR MIGUEL

1143. LUIS, Leopoldo de. "Dos poetas del 27," en Diario Córdoba, Cuadernos del Sur (9 dic. de 1999), 26 (ilustrado).

Comenta la huella de Celestina en "Huerto de Melibea» (J. Guillén, $1954,1960)$ y en dos poemas de Diálogos del conocimiento (V. Aleixandre, 1974).

1144. MARTÍN-ARAGÓN ADRADA, F. Julián. Los saberes médicosen 'La Celestina'. Toledo: Dip. Provincial de Toledo, 1998. Rústica, 124 pp. Ilustrado con fotos y dibujos. La capa reproduce "La madre Celestina» de Goya.

Lo que fue tesis doctoral (1962)y regalo de congreso (1974), ahora se re-edita para el V Centenario (texto en 29-122). Un análisis del texto celestinesco por un médico con el gol de exponer el contenido y losa conocimientos medicinales atesorados en el texto de Celestina.

1145. MATEO GÓMEZ, I., \& J. MATEO VIÑES. "La Celestina. Fuente mitológica para el Retablo San Pelayo del Maestro de Becerril: 
Comitente y autor." Archivo Español de Arte, no. 287 (1999), 289303 (ilustrado).

Las representaciones de Minerva (con el can), Pasiphae, Dido, Aeneas, y otras figuras mitológicas en un retablo de Palencia (hoy en Málaga) como posiblemente derivadas del conocimiento del texto celestinesco.

1146. MAURIZI, F. "La escala de amor de Calisto." Celestinesca 22.1 (Otoño 1998), 49-60.

La alegoría de la fortaleza escalada, tópico del amor cortés practicado en verso y prosa antes de Celestina, está invertida, desalegorizada, en la retórica de la Tragicomedia. Se desmitifica el amor idealizado entre nobles al convertirlo en un trato carnal.

1147. MENENDEZ PELAEZ, Jesús. "El Libro de buen amor," en Diario Córdoba, Cuadernos del Sur (9 dic. de 1999), 16-17 (ilustrado).

Medita, con ejemplos, las semejanzas entre el didactismo y la parodia comunes al Libro de buen amor y Celestina y, al mismo tiempo compara y contrasta las dos alcahuetas.

1148. MERINO, Margarita. "Ambigüedad y plenitud," en Diario Córdoba, Cuadernos del Sur (9 dic. de 1999), 7 ((ilustrado).

Elogios al "libro más amargo de la literatura española," y su mensaje plural.

1149. MICHELENA, Itziar. Dos «Celestinas»y una ficción. Filología y Lingüística 2, Bilbao: Servicio Editorial Univ. del País Vasco, 1999. Rústica, 126 pp.

Las dos "Celestinas" son la del primer autor y la de Rojas. Pretende explicar, partiendo de las diferencias observadas entre ellas, ciertos mecanismos que hacen que las dos coexistan dentro de un conjunto donde es difícil percibir fisuras. Se concentra en escenarios, personajes, casas y la representación del tiempo.

1150. MIGUEL MARTÍNEZ, Emilio de. "Encuentros y desencuentros con el lenguaje celestinesco." Ínsula, no. 633 (sept. 1999), 3-6 (ilustrado).

Un interesante recorrido por el léxico de la Comedia y los ajustes que son necesarios hoy día para no alejar al lector moderno de una recepción apropiada. Convincentes y numerosos ejemplos según 
distintas categorías: arcaísmos, latinismos, frases hechas, refranes, y problemas de claridad y de morfosintaxis.

1151. _ _ "La dificultad del lenguaje," en Diario Córdoba, Cuadernos del Sur (9 dic. de 1999), 13-14 (ilustrado).

Se habla de una Celestina con actualización léxica (versión Comedia) sobre los modernos repuestos que ha manejado (palabras desfasadas, latinismos y refranes con versiones modernas) al adaptar/modernizar el texto [Salamanca 1999]. Es una versión abreviada del estudio 1150.

1152. MINGUEZ MARTÍN, Luis. Melibea o la enfermedad del amor. Col. Arte, Literatura y psique 1, Zamora: Edintras, 1998.78pp. $\left(^{*}\right)$

1153. MONTES, Carolina. "Calisto, enfermo de amor." La Voz de Galicia, secc. "Culturas» (27 abril 1999), 2.

Sobre el impacto de los tratados de Bernardo Gordonio y del Dr. López Villalobos en la conceptualización del 'amor hereos', la enfermedad de amor de que padece Calisto.

1154.MORA, Arnoldo. "Don Juan y la Celestina: arquetipos mítico-estéticos." Káñina 16.2 (1992), 123-127.

Son dos creaciones-mitos de pueblo/tradición (siguiendo a Jung) que se han universalizado, usadas en este artículo para ensalzar 'el genio de la lengua castellana.'

1155. NEPOMUCENO, M. A. "La 'Repetición de amores'," en Diario Córdoba, Cuadernos del Sur (9 dic. de 1999), 20-21 (ilustrado).

Datos y especulaciones sobre las relaciones entre Juan de Lucena y su Repetición de amores y Rojas y Celestina. Sugiere que son tantas las semejanzas que posiblemente fuera Lucena que le entregó a Rojas el primer acto casi en el momento de abandonar España para Italia con intención de evitar las garras de la Inquisición.

1156. O'NEILL, John (comp.). Celestina 1499-1999. A Checklist of Editions, Translations, and Adaptations in the Library of The Hispanic Society of America. New York: HSA, 1999, 19 págs.

Lista cronológica de casi 175 Celestinas, con información bibliográfica. Con tres ilustraciones $(1499,1538)$. 
1157. PALAFOX, Eloísa. "De sabios, brujas y burdeles: Celestina y su mundo antiejemplar." Concentus Libri (Madrid), núm. 10 (octubre 1999),247252. Ilustrado.

Equipara a Celestina y su mundo prostibulario con la clase de los letrados en cuanto el abuso del saber en el siglo XV. Ambos saben vender muy caros sus saberes. La visión que del mundo se saca de Celestina es destructiva, mercantil y degradada.

1158. PALLA, María José. "Figuras literárias de magas e imagens do sabat na obra de Gil Vicente." Revista da Faculdade de Ciências Sociais e Humanas (Lisboa) 8 (1995), 297-312.

Unas cuantas referencias oblicuas a Celestina como importante antecedente de unas mujeres-magas en las obras de Gil Vicente.

1159. PARRILlA, Carmen. "Vieja, alcahueta y codiciosa." La Voz de Galicia, sección «Culturas» (27 abril 1999), 3.

Celestina tiene un pasado (textual) y los jóvenes que corrompe no, y eso le permite a la alcahueta la construcción de su propio mito, lo cual, en parte, facilita su manipulación de los demás. En este aspecto biográfico el autor centra la gravitas de su obra.

1160. (ilustrado).

Una lectura de Areúsa desde su primera mención en el primer auto y pasando por la Comedia, la Tragicomedia y en obras posteriores celestinescas (Feliciano de Silva, Sancho de Muñón). Su realización artística está trazada en una manera congruente, brillantemente matizada.

1161. . "Moralejas para todos los paladares." La aventura de la Historia, 1.12 (oct. 1999), 64-67 (ilustrado).

Un ameno recorrido por la crítica principal desde Bataillon (1961) que termina reconociendo que Celestinaes capaz de suscitar y sostener varias interpretaciones y énfasis.

1162. . "Corrupta y bebedora," en Diario Córdoba, Cuadernosdel Sur (9 dic. de 1999), 19 (ilustrado). 
Celestina, figura central, con narrar su autobiografía pasada y presente, crea su propio mito y por eso pasa a ser centro de gravedad de una obra destinada a la juventud.

1163. PEDRAZA JIMÉNEZ, Felipe B. "La tragicomedia en los escenarios." La Aventura de la Historia, 1.12 (oct. 1999), 72-75 (ilustrado).

Recoge aquí un rico panorama de los intentos en el siglo XX de escenificar a Celestina (directores, actrices, países, etc.)

1164. . "La integridad dramática," en Diario Córdoba, Cuadernos del Sur (9 dic. de 1999), 30-31 (ilustrado).

Defiende la idea de Rojas como dramaturgo sin escenario, hace alarde de la alta calidad literaria de su discurso dramático, y sugiere que, hoy, una representación (o lectura) completa no sería mal recibida.

1165. PÉREZ LÓPEZ, Manuel M. " "Calisto y Melibea se casaron ...»(visión modernista de La Celestina). "Ínsula, no. 633 (sept. 1999), 27-28.

Un análisis del sentimiento trágico en la obra celestinesca de Azorín, «Las nubes».

1166. PÉREZ PRIEGO, M. A. "Descendencia teatral de La Celestina."Ínsula, no. 633 (sept. 1999), 24-25 (ilustrado).

Destaca la potencia dramática que Celestina legó a Encina, Torres Naharro, Huete, las Natas y el anónimo autor del Auto de Clarindo, cual modelo directo de temas y situaciones. Luego hay menciones de Juan de la Cueva, Romero de Cepeda, Lope, Quevedo y Calderón.

1167. PÉREZ RODRÍGUEZ, Luis. Ver BLANCO AMOR

1168. PIANTONE, G. "Le illustrazioni antiche della Celestina di Fernando de Rojas, 1499-1531, "Tesi di Laurea, Univ. di Roma "La Sapienza», 1996, 2 vols. Directores: P. Botta, F. Lobera Serrano. (*)

1169. PRIETO, Remedios. "Controversias de la obra," en Diario Córdoba, Cuadernos del Sur (9 dic. de 1999), 10 ((ilustrado).

Rojas, al retocar una obra anterior "completa y manuscrita," habría ideado la escena del conjuro (acto III) al justificar - para el público de aquel entonces - tan rápido cambio en Melibea. Sustenta esa hipótesis con otras observaciones a las secuencias temporales. 
1170. PUEBLA, Teo. 'La Celestina' Ilustrada. Edición Conmemorativa, La Puebla de Montalbán: Ayuntamiento, 1999, papel brillante, 95 págs.

Contiene varios preliminares [una presentación por Justino Juárez del Cero; un poema, "Los colores de la vida" de J. Benito de Lucas; y un ensayo por Chus TUDELILLA titulado "La Celestina, desde la pintura" igualmente ilustrado por Teo Puebla] a las pinturas especialmente comisionadas por La Puebla de Montalbán para adornar una edición de lujo de Celestina [ver 1178]. La serie incluye los personajes, un 'retrato' del autor, e ilustraciones a todos los actos (págs 31-89), además de otras seis serigrafías.

1171. RIVERA, Isidro J. "Performance and Prelection in the Early Printed Editions of Celestina." Celestinesca 22.2 (Otoño 1998), 3-20.

El esquema iconográfico de las tempranas Celestinas ayuda a concretar el código verbal, facilitando el trabajo de grupos de lectores que negocian, entre sus miembros, leyendo en voz alta, el significado de la obra. Si no podemos hablar ya de discurso mimético, estas características de la cultura de la imprenta indican una representación ("performance") más cercana al drama.

1172. RODRÍGUEZ PUERTOLAS, Julio. "Luces y sombras en La Celestina (1)." Ínsula, no. 633 (sept. 1999), 11-13.

Presenta textualmente las varias actividades asociadas con la noche y el amanecer en Celestina - el amar y el morir - y cómo éstas forman una parte esencial de su rica temática. La imagen de Calisto como vampiro es particularmente irresistible.

1173. ROHLAND DE LANGBEHN, R. La unidad genéricade la novela sentimental españolade los siglos XV y XVI. Papers of the Medieval Hispanic Research Seminar 17, London: Dept. of Hispanic Studies, Queen Mary \& Westfield College, 1999.

Uno de los subtextos de esta monografía es que Celestina es una superación crítica del género de la ficción sentimental $(41-73,79,96)$, De paso, vincula a la celestinesca la Penitencia de amor de Jiménez de Urrea $(53,60,78)$.

1174. ROJAS, Fernando de. La Celestina. Ed. de Maite Cabello; prólogo de Ignacio Amestoy. Col. Millenium, Madrid: «El Mundo»/Unidad Ed., 1999. 189 pp. Capa ilustrada por Raúl Arias. 
Edición de la $T C M$ para lectores, sin notas, sin bibliografía. El breve prólogo enfatiza el momento histórico de la aparición de la obra y su carácter como primer fenómeno de la era de la imprenta [apareció como artículo periodístico, "Celos y amor de una obra pionera", en El mundo (19 de mayo, 1999), pág. 66]), ilustrado con la portada de Sevilla 1518-1520 (aquí fechado mal).

1175. . Comedia de Calisto y Melibea (Burgos 1499). Ed. a cargo de Emilio de Miguel. Tesoro Bibliográfico 15, Salamanca: Univ. de Salamanca, 1999, 399 págs. Capa ilustrada.

Tomo que acompaña la nueva edición facsímil de Burgos 1499 (Salamanca 1999). Es una transcripción fiel de la Comedia, cara a cara con la modernización léxica del texto (labor de amor), ambas por E. de Miguel. Una sección de su nutrida introducción (31-52) elabora e ilustra los procedimientos usados en la modernización. No menos importantes son las secciones en donde se presenta el texto de Burgos y sus relaciones con otros textos posteriores, un verdadero "estado de la cuestión" bien realizado.

1176. . TCM (Zaragoza 1507). Toledo: Antonio Pareja Editor, 1999.

Bella edición facsímil de la primera $T C M$ conocida en lengua española, el único ejemplar completo que existe hoy y sólo recuperado en 1998. Esta Celestina forma parte de un volumen facticio [ver SNOW 1207] que incluye tres pliegos sueltos también raros: un anónimo en prosa sobre Fernán González, uno poético de Juan del Encina, y otro también poético - de Garci Sánchez de Badajoz.

1177. . TCM. Valencia: Juan Joffre, 1514. Edición facsímil, Valencia: Institució Alfons el Magnànim, 1999. 2 vols. 400 pp.

Viene la ed. facsímil (de BNM R/4870) ricamente reproducida y acompañada por un segundo tomo de edición paleográfica (ésta por N. Salvador Miguel y S. López-Ríos) y estudios de J. L. Canet, y P. Botta (resumidos en este suplemento).

1178. _. . LC. Edición en papel de lujo en gran formato, ilustrada por Teo PUEBLA y con un epílogo de J. RODRÍGUEZ-PUERTOLAS. La Puebla de Montalbán: Ayuntamiento, 1999. Encuadernado, 393 págs.

No pretende ser una edición crítica; se tilda de edición conmemorativa de la Comisión «La Celestina V Centenario 14991999". Las ilustraciones también se publican aparte (ver 1170). 
1179. . LC. Introd. y notas de Luis Blanco Vila. Madrid: Torre de Goyanes, 1999. Rústica, 306 pp.

Se trata de la $T C M$ ligeramente modernizada. La mayoría de las notas tratan el léxico. Sin ilustraciones, sin bibliografía. La introducción (921) va destinado a un público general y acentúa el alboroto del amor carnal en las tempranas letras.

1180. .LC. Ed. de Joaquín Benito de Lucas. Clásicos Libertarias, Madrid: Ed. Libertarias, 1999, rústica, 371 págs. Capa ilustrada.

Útil para estudiantes que inician su lectura. Incluye: una introducción de 35 págs. más el texto (anotado), un glosario, un repertorio de nombres propios, y varios apéndices (comentario a un fragmento del auto XII, una antología de temas afines, y trozos de opiniones críticas. Falla la bibliografía con sólo 15 entradas que llegan a sólo 1977 !

1181. . LC. Intro. y notas J. Alarcón Benito. Colección Clásicos Selección, Madrid: Edimat, 1999, rústica, 271 págs. Cubierta de Juan Manuel Domínguez.

La TCM completa. Apareció esta introd. ya en Clásicos Fraile en 1981. Su bibliografía de 14 entradas tiene sólo una posterior a 1950 ! Poquísimas notas. Para "1999" no ofrece en absoluto nada nuevo.

1182. . La Celestina. Clásicos Universales 32, Madrid: JM Ediciones, 1999, rústica, 252 págs. Capa ilustrada.

La TCM. La introd. (5-12)es sacada de Menéndez y Pelayo [Estudios de crítica históricay literaria, v. 3, 237-253], con un Vocabulario en 245-250. Sin bibliografía, notas u otras ilustraciones.

1183. . LC. TCM. Ed. y notas de D. S. Severin, introd. de S. Gilman. Area Temática-Literatura, Madrid: Alianza, 1998, rústica, 292 págs. Capa ilustrada.

Es esencialmente igual (la introducción, el texto, las notas y el cuadro cronológico) que las otras ediciones de la serie «El libro del bolsillo, Literatura española», cuya 20ª reimpresión salió en 1996.

1184. . $L C$. Transcripción y notas de Pilar G. Moreno. Notas prologales de E. M. Aguilera. Mil Años de la Literatura, Barcelona: Orbis-Fabbri, 1999, rústica, 236 págs. 
Esta edición de 1958 sigue reimprimiéndose sin notas y $\sin$ bibliografía. La misma editorial la había sacado en otra serie en 1996.

1185. . LC. TCM. Grandes genios de la literatura universal, Madrid: Club Internacional del Libro, encuadernado, 253 págs. Capa ilustrada [Melibea, Calisto, Celestina].

El prólogo (7-20) sin firma. Edición sin notas. Contiene el «Auto de Traso» [246-251].

1186. .LC. TCM. Versión teatral de Luis GARCÍA MONTERO. Fábula 119, Barcelona: Tusquets, 1999, rústica, 207 págs. Capa ilustrada con la foto de Nati Mistral (en Celestina).

El generoso prólogo de García Montero (11-65) se centra en "La complejidad creativa (o el buen tiro por la culata)." Hay una breve bibliografía (66-67). Divide su adaptación en dos partes, de 15 y 25 cuadros respectivamente). El único personaje celestinesco sin papel aquí es Crito.

a. El País, 25 sept. de 1999, "Babelia," p. 25, A. P. F.

1187. ROJAS, Fernando, adaptador. Comedia de Calistoy Melibea de Fernando de Rojas. 63 hojas.

Adaptación del texto original para una puesta en escena estrenada en La Puebla de Montalbán (31 julio-1 agosto, 1999). Esta adaptación comienza con el planto de Pleberio y termina en el momento en que Melibea está para suicidarse.

1188. ROMERA CASTILLO, José. "En los escenarios de hoy," en Diario Córdoba, Cuadernos del Sur (9 dic. de 1999), 32 (ilustrado).

Comentarios a la adaptación de G. Torrente Ballester para la producción de la Compañía Nacional de Teatro Clásico (1988).

1189. ROUHI, Leyla. "The Go-Between as Principal Literary Character: La Celestina," en su Mediation and Love: A Study of the Medieval GoBetween in Key European and Near Eastern Texts (Brill's Studies in Intellectual History 93, Amsterdam: Brill, 1999), 256-285.

Un estudio comparado que contextualiza a Celestina entre las alcahuetas musulmanas y las occidentales (anus, trotaconventos), superándolas todas en su aplicación del saber. Celestina crea un orden 
transgresivo comercial y sexual que compite con el de la sociedad oficial. En este estado de cosas contradictorio, Celestina se defiende como mediadora con un discurso que se impone al de los demás, no sólo a los amantes, sino que a los otros tipos que pululan en su entorno urbano. El texto recoge distintas actitudes contemporáneas hacia este tipo de mujer plurivalente.

1190. . " '...y otros treynta officios': The Definition of a Medieval Woman's Work in Celestina." Celestinesca 22.2 (Otoño 1998), 21-31.

El texto celestinesco deja ver una importante transición en la participación de la mujer en ciertas profesiones. Celestina es del tipo de vieja cuyos oficios no se definían muy precisamente; son permeables. La fijación de fronteras (definiciones, restricciones) en la práctica de y licenciación en los oficios surge a finales del s. XV, lo que nos deja ver en el texto celestinesco una diversidad de actitudes ante estos múltiples oficios de Celestina.

1191. SALVADOR MIGUEL, Nicasio. "Quinientos años de La Celestina. "La Voz de Galicia, secc. «Culturas» (27 abril 1999), 1-2.

Rojas no es converso aunque de familia conversa. Los críticos que atribuyen posturas o sentimientos judaizantes a Rojas no aclaran texto. Antes de 1902 (publicación por Serrano y Sanz de los documentos sobre su ascendencia), no se había discernido presencia conversa alguna en el texto celestinesco.

1192. . "Fernando de Rojas y La Celestina. "La aventura de la Historia, 1.12 (oct. 1999), 58-63 (ilustrado).

El enfoque es Rojas, el que acabó la obra iniciada por otro, siguiendo bien conocidas pautas dramáticas de su momento histórico en un ambiente de ebullición salmantino, pero cuyo estado de converso no aclara nada de su argumento. Útil la recomendación de seguir indagando en posible contactos con las enseñanza de la Facultad de Medicina para iluminar mejor la presentación de la magia en la obra.

1193. ___ . Fernando de Rojas y La Celestina, "en Tragicomediade Calisto y Melibea (Valencia, Juan Joffre, 1514). Estudios y edición paleográfica (Valencia: Inst. Alfons el Magnànim, 1999), 7-15.

Un repaso necesariamente breve de lo que se sabe y se ha dicho de Rojas y de su Celestina en el cual se destacan dos sugerencias: (1) estudiar más asiduamente todo lo referente al entorno urbano e 
universitario salmantino en la época de Celestina, y (2) ver ciertos paralelismos entre el dramatismo esencial del diálogo en Celestina y el de las obras de Valle-Inclán.

1194. , y Santiago LÓPEZ-Ríos (eds.), "Valencia 1514: edición paleográfica," en Tragicomedia de Calisto y Melibea (Valencia, Juan Joffre, 1514). Estudiosy edición paleográfica (Valencia: Inst. Alfons el Magnànim, 1999), 53-195.

Edición que respeta casi en su totalidad el original (excepciones solo en casos de la 's' alta y las distintas representaciones de la ' $r$ '. Las páginas de la transcripción reproducen el contenido preciso de las originales.

1195. SÁNCHEZ, Ana Belén. "La obra primigenia," en Diario Córdoba, Cuadernos del Sur (9 dic. de 1999), 15 (ilustrado).

Discusión de la Celestina de Palacio, sus dos copistas, y la importancia de este ms. para una futura edición crítica.

1196. SÁNCHEZ, Antonio. "¿Quién fue el autor?," en Diario Córdoba, Cuadernos del Sur (9 dic. de 1999), 6 ((ilustrado).

Dos hipótesis (una literaria, otra lingüística) que tienden a reducir el papel de Rojas en Celestina. Rojas es receptor de la "Carta" y no su autor. Y la distinción entre las definiciones y usos de 'auctor' y 'autor' parecen invitar a considerar la posibilidad de que Rojas era uno "que compone y saca a luz otras obras literarias."

1197. SÁNCHEZ ESCRIBANO, F. J. Picarescaespañola en traducción inglesa (ss. XVI y XVI). Antologia y estudios. Zaragoza: Autor, 1998.

Presenta P. Guardia Massó, en las págs. 53-55, unos datos históricoliterarios relevantes a la selección de la traducción de James Mabbe de la Tragicomedia (55-67):excerptos de los actos I, IV, XIV, y XIX.

1198. SARTORI, Beatriz. "La alcahueta, en el cine." El mundo (19 mayo 1999), pág. 67. Con fotos de Amparo Soler Leal y Térele Pávez (dos actrices que fueron Celestinas).

Breves notas sobre las películas de Gerardo Vera (1996), César Ardavín (1969) y Carlos Lizardi (1964). 
1199. SCARBOROUGH, Connie. "Celestina: mucho placer y poca lectura." Concentus Libri (Madrid), num. 10 (octubre 1999), 239-246.Ilustrado.

Una meditación sobre la grandeza de la problemática obra literaria y su poca acogida al nivel popular (es decir no como la acogida casi universal de Don Juan o Don Quijote).

1200. SEVERIN, Dorothy S. "Pármeno, Lazarillo y las Novelas Ejemplares." Ínsula, no. 633 (sept. 1999), 26-27 (ilustrado).

Ecos claros del tipo que es Pármeno, transformado primero en Lazarillo y, después, en el perro Berganza y en Rinconete y Cortadillo cervantinos.

1201. . Mena's Maga, Celestina's Spell, and Cervantes' Witches," Donaire [London] 13 (1999), 36-38.

Detalles de hechicería pasadas intertextualmente del Laberinto de la Fortuna a Celestinay de ahí a «El Coloquio de los perros».

1202. . "El público de Celestina" del manuscrito a la imprenta." Concentus Libri (Madrid), num. 10 (octubre 1999),264-266. Ilustrado.

Apunta hacia el carácter de Rojas, tanto en el Prólogo como en el curiosos manuscrito de parte del primer acto (II.1520 de la Biblioteca de Palacio), como constante revisor, corrector y creador de su prosa.

1203. SNOW, J. T. "Alisa, Melibea, Celestina y la magia." Ínsula, no. 633 (sept. 1999), 15-18 (ilustrado).

Una lectura y un análisis pormenorizados de la figura de Alisa con los cuales pretende explicar el nulo efecto de la magia en la actuación de Alisa y de Melibea en la trama de Celestina.

1204. _._. "Celestina: Metateatro," en Studia HispanicaMedievalialV. Actas de las $V$ Jornadas Internacionales de Literatura Española Medieval (1996)(Buenos Aires: Pontificia Univ. Católica Argentina, 1999), 3447.

El concepto de vida como teatral en el mundo de Celestina explorado a través de ciertas escenas que funcionan como pequeñas representaciones, farsas y entremeses (hay 37 nombrados en un apéndice). Los personajes a veces son actores y otras veces, sépanlo o no, sirven de público de otras actuaciones. 
1205. . "Fernando de Rojas," en Encyclopedia of the Renaissance, ed. Paul F. Grendler et al, vol. 5 (New York: Charles Scribner's Sons, 1999), 346-348.

Ofrece un breve panorama de Rojas y Celestina en una nueva obra de consulta.

1206. . "Celestinas facsimilares." Concentus Libri (Madrid), num. 10 (octubre 1999), 259-263. Ilustrado.

Un breve repaso de las ediciones de Celestina sacadas en facsímil en el siglo XX. Termina mencionando unas Celestinas cuya importancia pide que también se saquen ediciones facsimilares [p. ej., Salamanca 1570].

1207. . "La Tragicomediade Calisto y Melibeade 1507," en Un Volumen Facticio de Raros Post-IncunablesEspañoles, coord. J. Martín Abad (Toledo: Antonio Pareja, 1999), 28-39; con trad. al inglés en 126-137.

Examina la historia de esta edición desde los inicios hasta el siglo XX, pasando por su aparición y utilización por T. Gorchs 1840 (ejemplar falto de sus primeras cuatro hojas) y la recuperación en 1988 de un ejemplar completo, editado en 1999 [ver 1176].

1208. , \& Lola COLOMINA. "Celestina de Fernando de Rojas: documento bibliográfico (vigésimo segundo suplemento). " Celestinesca 22.2 (Otoño 1998), 89-108.

Agregan unas 85 entradas más a las que se encuentran en los suplementos que publica la revista desde 1985 .

1209. . Ver CHERCHI

1210. TENORIO MATANZO, Pedro. "La Celestina (finales del s.V),"en su Iniciación a la literatura española en lengua castellana (Torrejón de Ardoz: Akal, 1987, 19944), 54-75.

Narra la historia a base de excerptos del texto (actos I, IV, IX, XII, $\mathrm{XX}, \mathrm{XXI}$ ). Añade unos ejercicos para guiar el estudio del texto por los alumnos.

1211. TORRES NEBRERA, Gregoria. "¿Es una obra feminista?," en Diario Córdoba, Cuadernos del Sur (9 dic. de 1999), 34-35 (ilustrado). 
Se basa en la cita de Heráclito sobre la contienda entre todas las cosas para defender un feminismo avant la lettre en la Tragicomedia. Dos hitos: las auto-defensas de Celestina (auto XII) y de Melibea (auto $\mathrm{XX}$ ).

1212. VILAR, M. "La Celestina na pintura." La Voz de Galicia, secc. «Culturas» (27 abril 1999), 8.

Ilustrado con el cuadro de Picasso (blanco y negro) de h. 1904. Luego sólo nombres: Murillo, Luis Paret, Zuloaga, Goya, Picasso (de españoles) o los de Peter Huyas, Massys, Aelst, Lucas de Leyden (de pintores del norte de Europa).

1213. VILLENA, Fernando de. "Hipótesis sobre la obra," en Diario Córdoba, Cuadernos del Sur (9 dic. de 1999), 33 (ilustrado).

Recreación imaginativa de unas tertulias mantenidas en casa de Rojas (con lecturas de Celestina). Después, un criado descubre a otro más joven (el que narra) que Rojas había comprado en el Zocodover de Toledo los bártulos del desgraciado Rodrigo de Cota, incluso el manuscrito de la Tragicomedia. Luego Rojas diría tan a menudo que él lo escribió todo menos "el primer auto," que acabaría por creerlo él mismo.

1214. WEDEL, Alfred R. "La presencia de la Celestina en Alemania: errores de interpretación." Concentus Libri (Madrid), num. 10 (octubre 1999), 253-262. Ilustrado.

Concentra en algunos errores en las traducciones de Christof Wirsung al alemán $(1520,1534)$ por haber confiado éste en, como intermediario, la traducción italiana de Hordognez. Concluye que había una mentalidad alemana no muy preparada para algunos de los excesos mediterráneos.

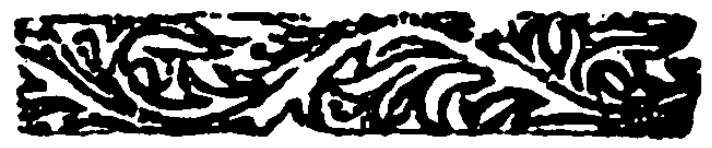

